\title{
Consequences of the combined loss of BOK and BAK or BOK and BAX
}

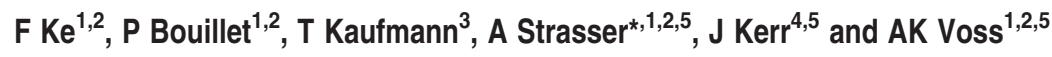

The multi-BCL-2 homology domain pro-apoptotic BCL-2 family members BAK and BAX have critical roles in apoptosis. They are essential for mitochondrial outer-membrane permeabilization, leading to the release of apoptogenic factors such as cytochrome$c$, which promote activation of the caspase cascade and cellular demolition. The BOK protein has extensive amino-acid sequence similarity to BAK and BAX and is expressed in diverse cell types, particularly those of the female reproductive tissues. The BOK-deficient mice have no readily discernible abnormalities, and its function therefore remains unresolved. We hypothesized that BOK may exert functions that overlap with those of BAK and/or BAX and examined this by generating $\mathrm{Bok}^{-1-} \mathrm{Bak}^{-1-}$ and $\mathrm{Bok}^{-1-} \mathrm{Bax}^{-1-}$ mice. Combined loss of BOK and BAK did not elicit any noticeable defects, although it remains possible that BOK and BAK have critical roles in developmental cell death that overlap with those of BAX. In most tissues examined, loss of BOK did not exacerbate the abnormalities caused by loss of BAX, such as defects in spermatogenesis or the increase in neuronal populations in the brain and retina. Notably, however, old Bok ${ }^{-1-} \mathrm{Bax}^{-1-}$ females had abnormally increased numbers of oocytes from different stages of development, indicating that BOK may have a pro-apoptotic function overlapping with that of BAX in age-related follicular atresia.

Cell Death and Disease (2013) 4, e650; doi:10.1038/cddis.2013.176; published online 6 June 2013

Subject Category: Experimental Medicine

Apoptosis, or programmed cell death, is a vital physiological process that regulates tissue homeostasis by removing excess and damaged cells. ${ }^{1}$ It is also responsible for morphogenesis during embryo development, for instance, by elimination of interdigital webs. ${ }^{2}$ Deregulated apoptosis can lead to the accumulation of unwanted cells, and such defects have been implicated in a range of diseases such as cancer and autoimmunity. ${ }^{1}$

There are two main pathways to apoptosis ${ }^{3}$ - the 'death receptor' (also called 'extrinsic') ${ }^{4}$ and the 'BCL-2-regulated' (also called 'mitochondrial', 'intrinsic' or 'stress') pathway, ${ }^{5}$ both culminating in the activation of caspases that effect cellular destruction. The 'BCL-2-regulated' pathway is controlled by the $\mathrm{Bcl}-2$ family of proteins, which can be divided into three sub-groups according to structure and function. The anti-apoptotic members, BCL-2, BCL- $\mathrm{X}_{\mathrm{L}}, \mathrm{MCL}-1, \mathrm{BCL}-\mathrm{W}$ and $A 1$, share four regions of homology (called BCL-2 homology $(\mathrm{BH})$ domains) and are vital for cell survival. Pro-apoptotic members can be further classified into two sub-groups - the multi-BH domain pro-apoptotic proteins BAX and BAK (and possibly BOK, see below), which are critical to unleash the effector phase of apoptosis, and the BH3-only proteins (BID,
BIM, BAD, BIK, BMF, NOXA, PUMA and HRK), which are essential for the initiation of apoptosis signaling. ${ }^{5}$

Developmental cues and stress stimuli cause transcriptional and/or post-transcriptional activation of the BH3-only proteins. ${ }^{6}$ These proteins initiate apoptosis either by direct activation of BAX/BAK, or indirectly by binding to the antiapoptotic BCL-2 family members, thereby unleashing BAX and BAK from their restraint by the former. ${ }^{7,8}$ Activation of BAX and BAK constitutes the 'point of no return' in apoptosis signaling. This initiates the effector phase of cell death by causing mitochondrial outer-membrane permeabilization, resulting in the release of apoptogenic factors (e.g., cytochrome- $c$ and SMAC/DIABLO) that activate the caspase cascade to mediate cellular demolition. ${ }^{9}$

Biochemical and genetic experiments have revealed the functions of BAX and BAK, and single-knockout mice deficient for $\mathrm{BAX}^{10}$ or $\mathrm{BAK}^{11}$ have previously been generated. These animals were healthy and appeared outwardly normal, but adult $\mathrm{Bax}^{-/-}$males show testicular atrophy and are infertile with complete absence of mature sperm in the seminiferous tubules. ${ }^{10}$ Moreover, lymphoid tissues from $\mathrm{Bax}^{-/-}$mice display mild hyperplasia, although lymphocytes isolated from

\footnotetext{
${ }^{1}$ The Walter and Eliza Hall Institute of Medical Research, Melbourne, Victoria, Australia; ${ }^{2}$ Department of Medical Biology, University of Melbourne, Melbourne, Victoria, Australia; ${ }^{3}$ Institute of Pharmacology, University of Bern, Bern, Switzerland and ${ }^{4}$ Department of Anatomy and Developmental Biology, Monash University, Clayton, Victoria, Australia

${ }^{*}$ Corresponding author: A Strasser, The Walter and Eliza Hall Institute of Medical Research, 1G Royal Parade Parkville, Melbourne, Victoria 3052, Australia. Tel: +61 39345 2555; Fax: +61 39347 0852; E-mail: strasser@wehi.edu.au

${ }^{5}$ These authors share senior authorship.

Keywords: apoptosis; BOK; BAX; BAK; development

Abbreviations: APC, allophycocyanin; BCL-2, B cell lymphoma 2; BH, BCL-2 homology; BM, bone marrow; CC, corpus callosum; CP, choroid plexus; Ctx, cerebral cortex; DG, dentate gyrus; FACS, fluorescence-activated cell sorting; FasL, Fas ligand; FCS, fetal calf serum; FITC, fluorescein isothiocyanate; Hi, hippocampus; HN, habenular nuclei; Ht, hypothalamus; LN, lymph nodes; LV, lateral ventricle; PI, propidium iodide; R-PE, red phycoerythrin; Se, septum; Str, striatum; Th, thalamus; 3V, third ventricle

Received 22.4.13; accepted 23.4.13; Edited by G Raschellà.
} 
these animals were reported to undergo cell death at a normal rate in response to a range of apoptotic stimuli in vitro. ${ }^{10,11}$ Conversely, Bak ${ }^{-/-}$mice are fertile and histological evaluation revealed no major defects in their organs; notably, these animals did not develop any diseases even when aged past 1 year. $^{11}$

Remarkably, the combined absence of BAX and BAK causes several serious phenotypic aberrations that are never observed in the singly BAX- or BAK-deficient animals. ${ }^{11}$ Less than $10 \%$ of $\mathrm{Bax}^{-/-} \mathrm{Bak}^{-/-}$mice reached adulthood, and the few survivors displayed abnormalities that are characteristic for defects in programmed death of epithelial cells, such as persistent interdigital webbing, imperforate vagina and supernumerary neural progenitor cells in the neurogenic subventricular zone of the forebrain. ${ }^{11,12}$ Moreover, mice reconstituted with a BAX/BAK doubly deficient hematopoietic system developed lymphadenopathy and systemic autoimmune disease. ${ }^{12,13}$ As $\mathrm{Bax}^{-/-} \mathrm{Bak}^{-/-}$lymphoid cells are markedly resistant to diverse apoptotic stimuli such as growth factor deprivation, treatment with glucocorticoids or DNAdamaging drugs, ${ }^{12,13}$ these findings demonstrate that $\mathrm{BAX}$ and BAK have largely overlapping roles in the intrinsic apoptotic pathway.

Intriguingly, several major organs that are widely believed to be shaped by programmed cell death, such as the kidney, lungs, heart and liver, appeared normal in the Bax ${ }^{-/-}$ $\mathrm{Bak}^{-/-}$mice. $^{11}$ Hence, it has been postulated that BAX/ BAK-independent processes may have a role in programmed cell death in morphogenesis. BOK (also called MTD in humans) shares extensive $(\sim 70 \%)$ amino-acid sequence similarity with the multi-BH domain pro-apoptotic proteins and has therefore been hypothesized to function in a BAX/BAKlike manner. ${ }^{14}$ We have previously generated BOK-deficient mice; like BAX or BAK singly deficient animals, Bok ${ }^{-/-}$mice developed normally and were healthy; moreover, their leukocytes were normally sensitive to diverse cytotoxic stimuli. ${ }^{15}$ We have therefore now explored the possibility that BOK may have functions that overlap with those of BAK or $\mathrm{BAX}$ by generating $\mathrm{Bok}^{-/-} \mathrm{Bak}^{-/-}$and $\mathrm{Bok}^{-/-} \mathrm{Bax}^{-/-}$ mice. Because the function of BOK has not yet been clearly defined to date, analysis of these doubly deficient mice may aid in providing insight into whether BOK functions in a BAX/ BAK-like pro-apoptotic manner.

\section{Results}

Generation of $\mathrm{Bok}^{-/-} \mathrm{Bak}^{-/-}$and $\mathrm{Bok}^{-/-} \mathrm{Bax}^{-/-}$ mice. Bok ${ }^{-/-},{ }^{15} \mathrm{Bak}^{-/-11}$ and $\mathrm{Bax}^{-/-}$mice ${ }^{10}$ have been previously generated in our laboratory or the laboratories of others. These animals were intercrossed to produce mice doubly deficient for BOK and BAK, or BOK and BAX. Offspring from intercrosses of $\mathrm{Bok}^{-/-} \mathrm{Bak}^{+/-}$mice and intercrosses of $\mathrm{Bok}^{-/-} \mathrm{Bax}^{+/-}$mice were genotyped at 4 weeks of age (Supplementary Figure 1). The results revealed that $\mathrm{Bok}^{-1-} \mathrm{Bak}^{-/-}$and $\mathrm{Bok}^{-/-} \mathrm{Bax}^{-/-}$offspring were obtained at the expected Mendelian ratio from such matings (Table 1). The Bok ${ }^{-/-} \mathrm{Bak}^{-/-}$and $\mathrm{Bok}^{-/-} \mathrm{Bax}^{-/-}$mice both appeared outwardly normal and healthy when monitored for up to 12 months of age, with no obvious phenotypic abnormalities. However, males lacking both BOK and BAX, like BAX singly deficient males, were sterile. This supports earlier findings that BAX is essential for normal spermatogenesis in mice. In contrast, the BOK/BAK doubly deficient mice could be interbred to produce $\mathrm{Bok}^{-/-} \mathrm{Bak}^{-/-}$offspring, demonstrating that the combined absence of BOK and BAK does not compromise female or male fertility in mice.

These results show that in contrast to the combined loss of $B A X$ and $B A K,{ }^{11}$ double deficiencies in BOK and BAX, or BOK and BAK, do not cause more severe developmental abnormalities than those already observed in the respective singleknockout animals.

Lymphoid organ analysis in young and aged Bok ${ }^{-/-}$ demonstrated important and largely overlapping roles of BAK and BAX in the developmentally programmed and cytotoxic stress-induced death of lymphoid cells. ${ }^{12,13}$ The loss of BAX alone was shown to cause mild splenic hyperplasia because of an abnormal increase in lymphocyte numbers. ${ }^{10}$ Young $B o k^{-1-}$ females also displayed a minor increase in spleen and thymus weights, although this was most likely not caused by an increase in hematopoietic cells. ${ }^{15}$ To determine whether the combined absence of BOK together with loss of BAX or BAK would lead to marked aberrations of the lymphoid system, we compared the hematopoietic cell subset compositions in peripheral blood, bone marrow, spleen and thymus of $\mathrm{Bok}^{-/-} \mathrm{Bax}^{-/-}$and $\mathrm{Bok}^{-/-} \mathrm{Bak}^{-/-}$ animals with those from age- and sex-matched wild-type and single-knockout $\left(\mathrm{Bok}^{-/-}, \mathrm{Bax}^{-/-}\right.$and $\left.\mathrm{Bak}^{-/-}\right)$controls.

In contrast to an earlier report, ${ }^{10}$ we did not detect a significant increase in the spleen and thymus weights of $\mathrm{Bax}^{-/-}$mice in comparison with wild-type controls at 9-14 weeks of age (Figures $1 \mathrm{a}$ and b). Instead, we found that $\mathrm{Bak}^{-/-}$females had a minor increase in spleen weight, but this was not seen in $\mathrm{Bak}^{-1-}$ males. The $\mathrm{Bok}^{-/-} \mathrm{Bak}^{-/-}$and $\mathrm{Bok}^{-/-} \mathrm{Bax}^{-/-}$mice displayed normal spleen and thymus weights at this age (Figures $1 a$ and $b$ ). The total numbers of hematopoietic cells in the spleen, thymus, bone marrow and blood of $\mathrm{Bok}^{-1-} \mathrm{Bax}^{-1-}$ and $\mathrm{Bok}^{-/-} \mathrm{Bak}^{-1-}$ mice were comparable to those found in wild-type controls (Figures $2 a-$ d, Supplementary Figures 2a-d). Fluorescence-activated cell sorting (FACS) analysis of splenocytes and blood revealed that young adult (9-14 weeks) Bok ${ }^{-/-} \mathrm{Bax}^{-/-}$and Bok ${ }^{-/-}$ $\mathrm{Bak}^{-{ }^{-}-}$animals contained normal numbers of $\mathrm{B}$ as well as $\mathrm{T}$ lymphocytes, granulocytes and macrophages. Young $\mathrm{Bok}^{-/-} \mathrm{Bax}^{-/-}$and $\mathrm{Bok}^{-/-} \mathrm{Bak}^{-/-}$animals also had normal numbers of the $\mathrm{CD} 4^{-} \mathrm{CD}^{-}, \mathrm{CD}^{+}{ }^{+} \mathrm{CD} 8^{+}, \mathrm{CD} 4^{-}$ $\mathrm{CD}^{+}$and $\mathrm{CD}^{+}{ }^{+} \mathrm{CD}^{-}{ }^{-}$-lymphoid cell subsets in their thymi as well as normal numbers of B-lymphoid cell subsets, erythroid cells, granulocytes and macrophages in their bone marrow (Figures 2a-d, Supplementary Figures 2a-d). Some minor differences were observed: for instance, $\mathrm{Bok}^{-/} \mathrm{Bax}^{-/}$

females had increased numbers of eosinophils in the blood compared with wild-type females, but this was not observed in Bok ${ }^{-/-} \mathrm{Bax}^{-/-}$males (Figure 2d, Supplementary Figure 2d).

To determine whether the combinatorial loss of BOK and BAX, or BOK and BAK, would have an impact on hematopoiesis in aged mice, we also examined the lymphoid organs 
Table $1 \mathrm{Bok}^{-/-} \mathrm{Bak}^{-/-}$and $\mathrm{Bok}^{-/-} \mathrm{Bax}^{-/-}$doubly deficient animals are produced at the expected Mendelian frequency

\begin{tabular}{|c|c|c|c|c|c|c|}
\hline Genotype & Bok $^{+\prime+}$ & Bok $^{+\prime-}$ & Bok $^{-I-}$ & $n$ & $\chi^{2}$ value & $P$ \\
\hline $\mathrm{Bok}^{+/-} \times \mathrm{Bok}^{+/-}$ & $23 / 99(23.2 \%)$ & $51 / 99(51.5 \%)$ & $25 / 99(25.3 \%)$ & 99 & 0.941 & 0.948 \\
\hline $\mathrm{Bak}^{+1-} \times \mathrm{Bak}^{+1-}$ & $35 / 149(23.5 \%)$ & $79 / 149(53 \%)$ & $35 / 149(23.5 \%)$ & 149 & 0.873 & 0.907 \\
\hline $\mathrm{Bax}^{+1-} \times \mathrm{Bax}^{+1-}$ & $34 / 148(23 \%)$ & $85 / 148(57.4 \%)$ & $29 / 148(20 \%)$ & 148 & 0.395 & 0.403 \\
\hline $\mathrm{Bok}^{-/-} \mathrm{Bak}^{+/-} \times \mathrm{Bok}^{-/-} \mathrm{Bak}^{+/-}$ & $25 / 103(24.3 \%)$ & $57 / 103(55.3 \%)$ & $21 / 103(20.4 \%)$ & 103 & 0.678 & 0.678 \\
\hline $\mathrm{Bok}^{-1-} \mathrm{Bax}^{+1-} \times \mathrm{Bok}^{-1-} \mathrm{Bax}^{+1-}$ & $55 / 205(26.8 \%)$ & $104 / 205(50.7 \%)$ & $46 / 205(22.4 \%)$ & 205 & 0.808 & 0.817 \\
\hline
\end{tabular}
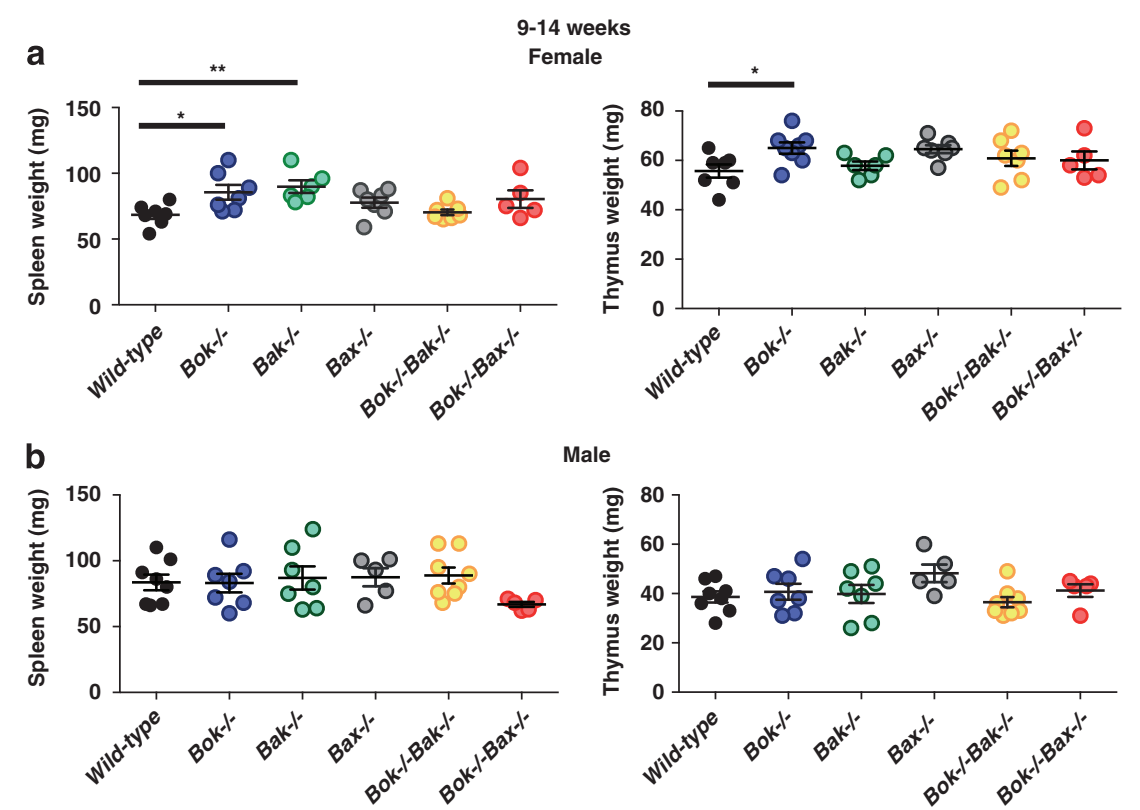

Figure 1 Spleen and thymus weights of female and male $B o k^{-/-} \mathrm{Bak}^{-/-}$and $B o k^{-/-} \mathrm{Bax}^{-/-}$double-knockout and control wild-type, as well as Bok ${ }^{-/-}$, Bak ${ }^{-/-}$ and $\mathrm{Bax}^{-/-}$single-knockout, mice were analyzed at 9-14 weeks (young cohort). Each data point represents an individual mouse. Results were separated into two groups: (a) females and (b) males. Statistically significant differences are indicated as * and ** for $P<0.05$ and $P<0.01$, respectively

of compound knockout animals that were aged up to 1 year. Similar to what we observed in young (9-14-week-old) animals, compound knockout (Bok ${ }^{-/-} \mathrm{Bax}^{-/-}$and Bok $\mathrm{Bo}^{-/-}$ $B a k^{-\prime-}$ ) male and female mice had spleen and thymus weights that were comparable to those from wild-type controls (Supplementary Figure 3). The total cellularity of the thymus and spleen, as well as the leukocyte cell subset composition of these tissues and the blood of $\mathrm{Bok}^{-1-} \mathrm{Bax}^{-1-}$ and $\mathrm{Bok}^{-/-} \mathrm{Bak}^{-/-}$mice were comparable to those of agematched wild-type controls (Supplementary Figures 4 and 5). However, detailed flow-cytometric analysis revealed minor differences in certain leukocyte populations between wildtype and compound knockout animals. For example, aged $\mathrm{Bok}^{-/-} \mathrm{Bax}^{-1-}$ females displayed a slight increase in CD4 ${ }^{+} \mathrm{CD}^{-}$thymocytes compared with wild-type animals (Supplementary Figure 4a), but $\mathrm{Bok}^{-/-} \mathrm{Bax}^{-/-}$males had normal numbers of all thymic cell subsets (Supplementary Figure 5a).

Despite these minor differences in leukocyte populations, male and female $\mathrm{Bok}^{-/-} \mathrm{Bak}^{-/-}$as well as $\mathrm{Bok}^{-/-} \mathrm{Bax}^{-1-}$ mice remained healthy with no signs of autoimmunity or hematopoietic malignancy up to at least 1 year of age. These observations demonstrate that BOK does not have significant overlapping functions with BAX or BAK in the development or maintenance of homeostasis in the hematopoietic system.
Impact of combined loss of BOK and BAX, or BOK and BAK, on lymphocyte survival in culture. BAX and BAK have critical, largely overlapping roles in the 'mitochondrial apoptotic' pathway. Lymphoid cells and fibroblasts from $\mathrm{Bax}^{-/-} \mathrm{Bak}^{-/-}$mice were highly resistant to diverse apoptotic stimuli, such as cytokine deprivation, DNA damage or ER stress, but cells lacking BAX or BAK alone were normally sensitive or displayed only minor resistance. ${ }^{11,13}$ To determine whether the combined loss of BOK and BAX, or $\mathrm{BOK}$ and BAK, might confer protection from apoptotic stimuli, we purified immature $\mathrm{CD} 4{ }^{+} \mathrm{CD}^{+}$thymocytes, mature T lymphocytes (both $\mathrm{CD}^{+}{ }^{+} \mathrm{CD}^{-}$and $\mathrm{CD} 4{ }^{-} \mathrm{CD} 8^{+}$) and $B$ lymphocytes from the lymph nodes, as well as neutrophils from the bone marrow, and cultured them in the presence of dexamethasone, etoposide, the BH3-mimetic ABT-737, Fas ligand (FasL) or simple medium (no added cytokines), the last to mimic growth factor deprivation. This analysis revealed that $\mathrm{CD}^{+}{ }^{+} \mathrm{CD} 8^{+}$thymocytes from both $B o k^{-/-}$ $\mathrm{Bax}^{-1-}$ and $\mathrm{Bok}^{-/-} \mathrm{Bak}^{-/-}$double-knockout mice were normally sensitive to all treatments tested (Supplementary Figure 6). Likewise, neutrophils, mature $\mathrm{B}$ and $\mathrm{CD} 4^{+}$as well

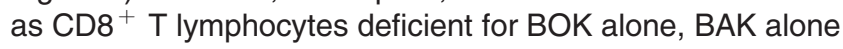
or even those lacking both BOK and BAK died at rates comparable to their wild-type counterparts in response to all apoptotic stimuli tested (Figure 3). In contrast, lymphocytes 
lacking $\mathrm{BAX}$ (i.e., mature $\mathrm{B}$ and $\mathrm{CD}^{+}{ }^{+}$as well as $\mathrm{CD}{ }^{+}$ $\mathrm{T}$ lymphocytes from $\mathrm{Bax}^{-/-}$or $\mathrm{Bok}^{-/-} \mathrm{Bax}^{-/-}$mice) displayed slightly higher resistance than their wild-type counterparts to treatment with etoposide, FasL or ABT-737 at earlier time points (Figure 3 , data points marked with ${ }^{*}$ ). However, the additional loss of BOK did not provide further protection to cells lacking BAX. These results show that BOK does not have a major overlapping role with BAX or BAK in
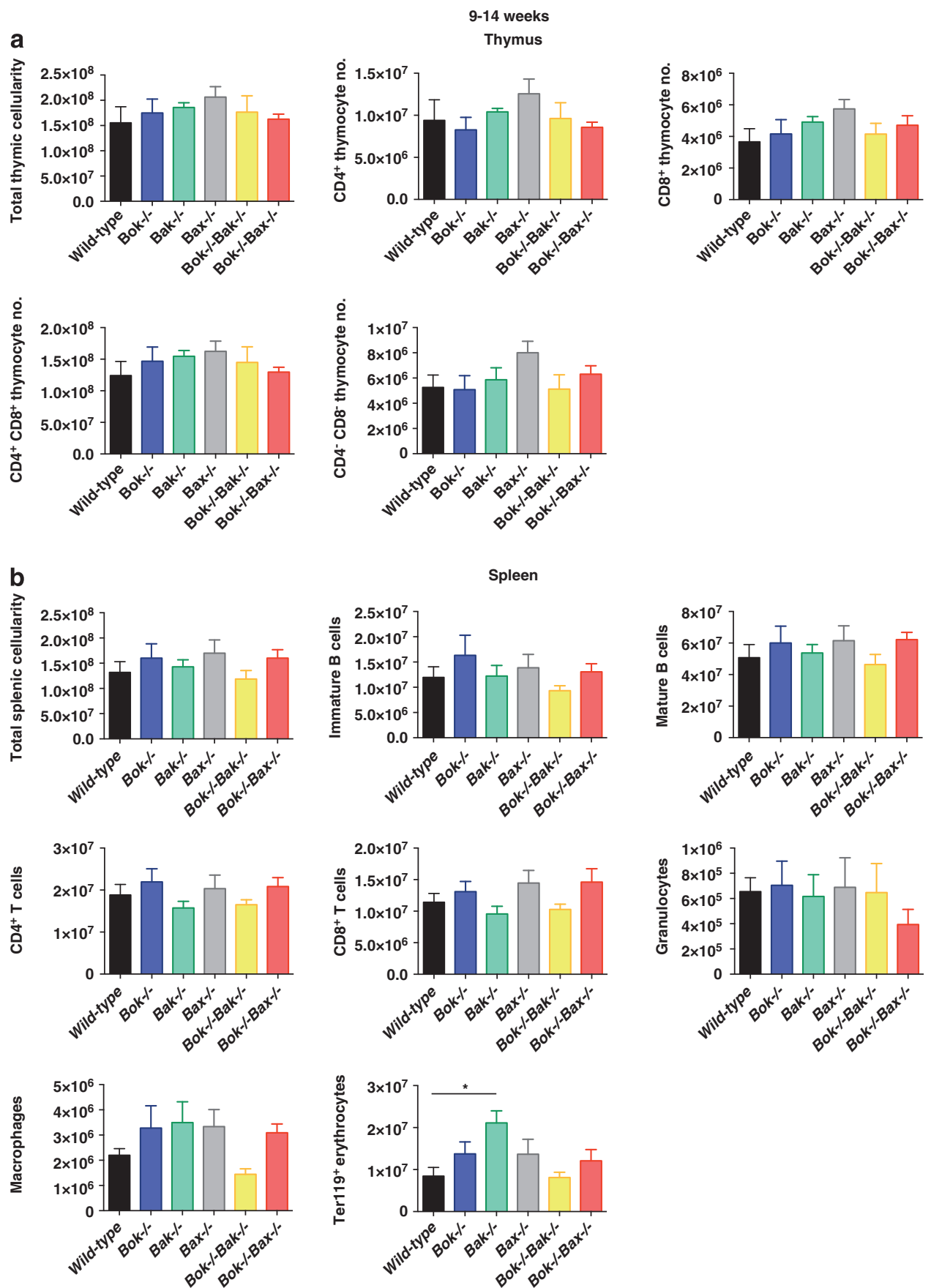

Figure 2 Lymphoid organ analysis of young adult female mice of the indicated genotypes at 9-14 weeks of age. The total numbers of lymphocytes in the (a) thymus, (b) spleen and (c) bone marrow of young female mice of the indicated genotypes were determined by automated cell counting. (a) Thymocyte sub-populations (CD4 ${ }^{-}$CD8 ${ }^{-}$, $\mathrm{CD}^{+} \mathrm{CD} 8{ }^{+}, \mathrm{CD}^{+}{ }^{+} \mathrm{CD} 8^{-}$and $\mathrm{CD} 4^{-} \mathrm{CD} 8^{+}$) were identified by staining with fluorochrome-conjugated antibodies against lineage-specific surface markers followed by FACS analysis. In the (b) spleen or (c) bone marrow, the percentages of immature (B220 ${ }^{+}$slgM $^{\text {hi }}$ slgD low $)$ and mature $B$ cells $\left(\mathrm{B}_{2} 20^{+} \mathrm{slgM}^{\text {low }}\right.$ slgD $\left.{ }^{\text {hi }}\right)$, macrophages

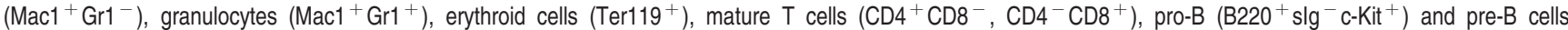
$\left(\mathrm{B}_{22} \mathrm{C}^{+} \mathrm{slg}^{-} \mathrm{C}\right.$-Kit') cells were similarly determined by cell counting and flow-cytometric analysis. (d) The numbers of leukocytes (per $\left.\mu l\right)$ in the peripheral blood were determined using the ADVIA automated blood machine. Data are presented as mean \pm S.E.M. of the total number of cells of a particular subset ( $n=4-5$ animals per genotype). Compare these findings with young adult male mice (Supplementary Figure 2), aged female mice (Supplementary Figure 4) and aged male mice (Supplementary Figure 5) 

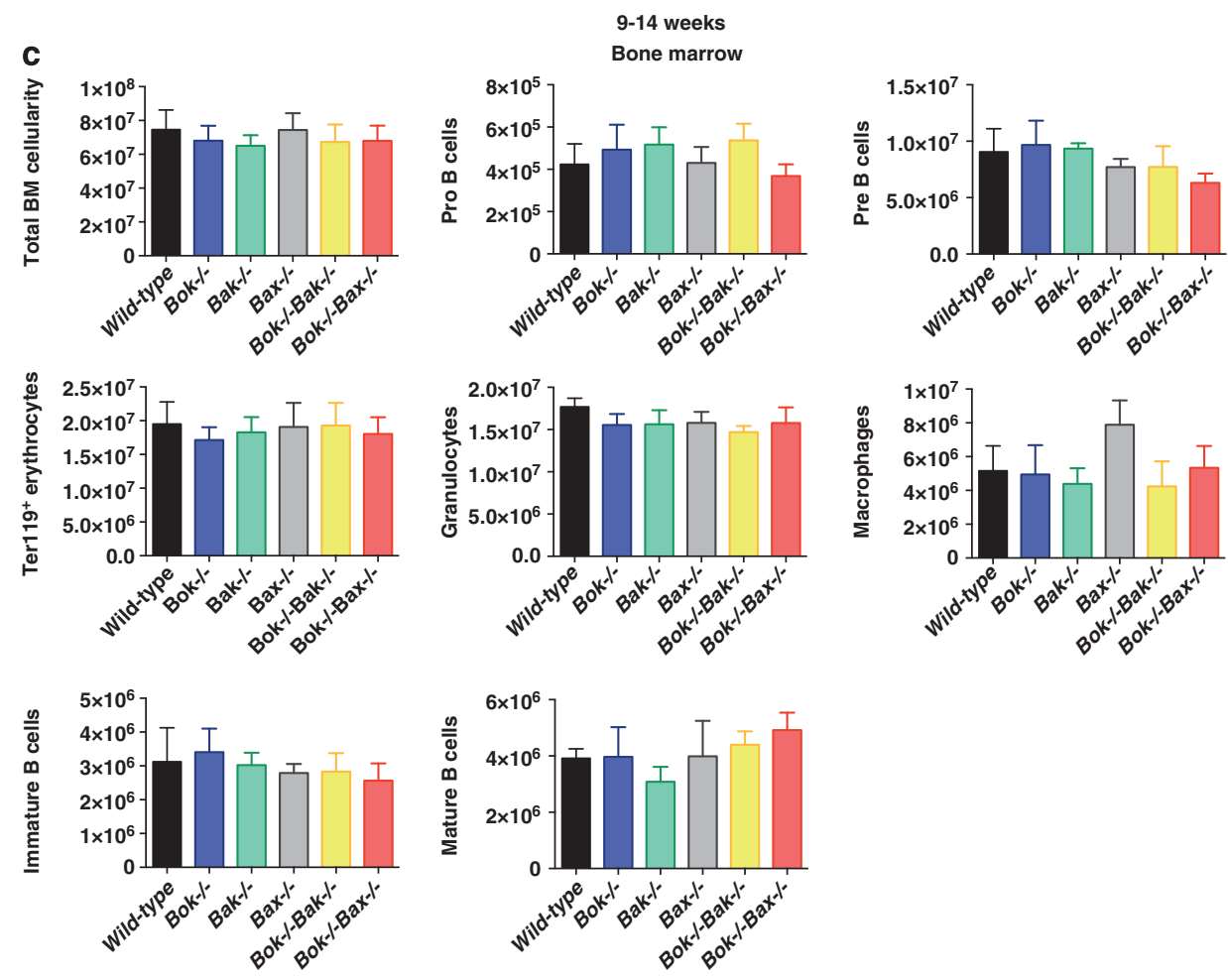

d
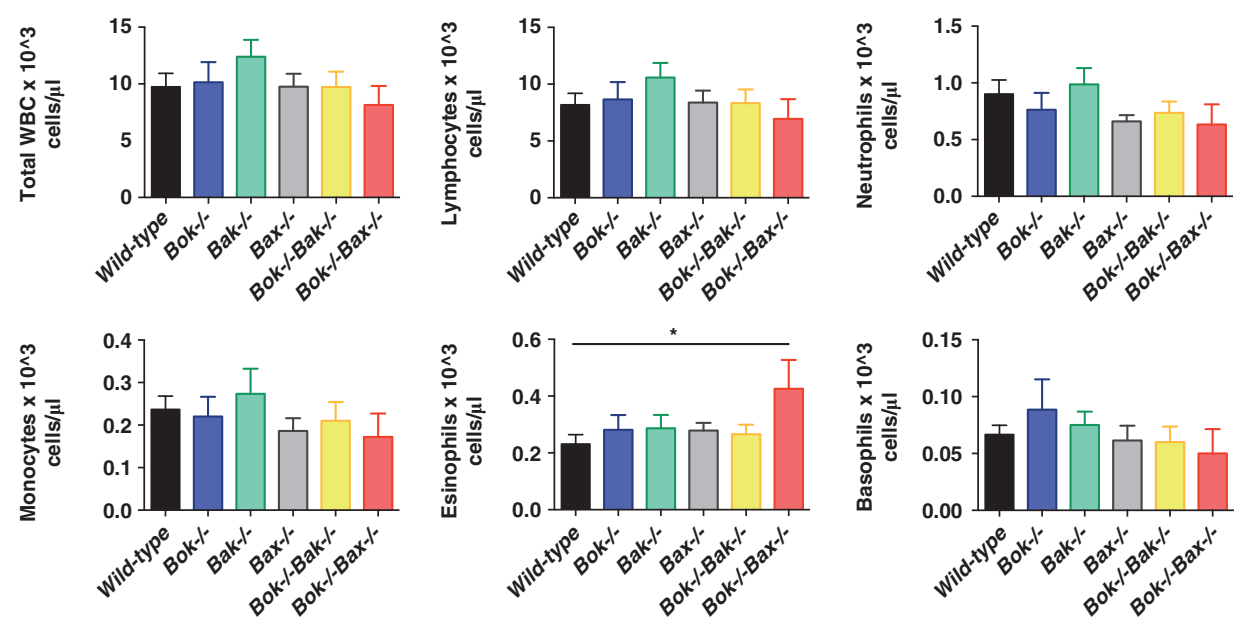

Figure 2 Continued

the response of lymphoid and myeloid cells to the apoptotic stimuli tested.

The concomitant loss of BOK in addition to BAX does not have a significant impact on the severity of the developmental abnormalities seen in $\mathrm{Bax}^{-/-}$mice. To further investigate whether the absence of BOK together with BAX or BAK would lead to developmental defects in organs apart from those that constitute the hematopoietic system, we examined other tissues including the liver, kidney, heart, lungs, brain, pancreas, testes, ovaries and retina of 14-week-old mice (comparing $\mathrm{Bok}^{-/-} \mathrm{Bax}^{-/-}$, $\mathrm{Bok}^{-/-} \mathrm{Bak}^{-/-}, \mathrm{Bok}^{-/-}, \mathrm{Bax}^{-/-}, \mathrm{Bak}^{-/-}$and wild-type animals). Previous studies have shown that mice lacking BOK, BAK or BAX alone did not exhibit any obvious abnormalities in their major organs, except that $B a x^{-/-}$ males had atrophic testes devoid of mature spermatocytes. ${ }^{10}$ To determine whether BOK may have a role in spermatogenesis in a manner overlapping with BAX or BAK, we examined young adult $\mathrm{Bok}^{-/-} \mathrm{Bak}^{-/-}$and $\mathrm{Bok}^{-/-} \mathrm{Bax}^{-/-}$males (914 weeks of age, Figure 4). Histological examination revealed that the testes from $\mathrm{Bok}^{-/-} \mathrm{Bak}^{-/-}$males were 
a

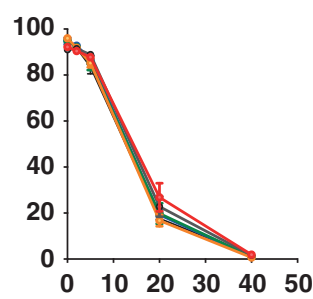

b

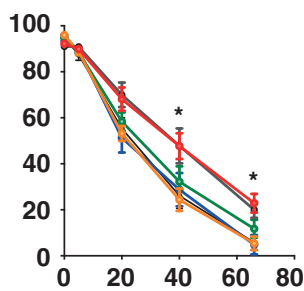

C

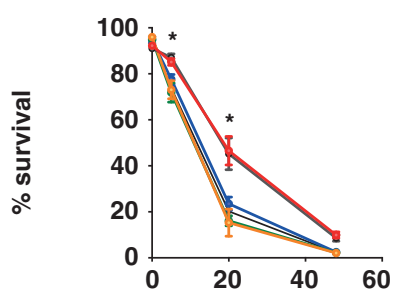

d

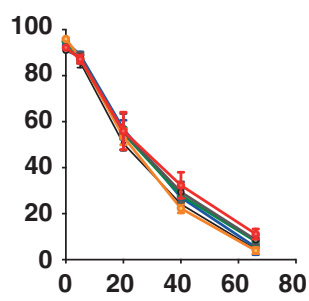

e

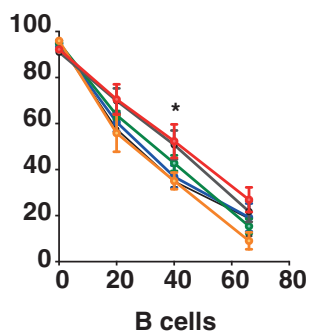

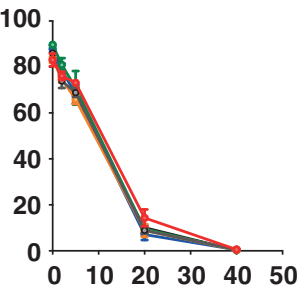
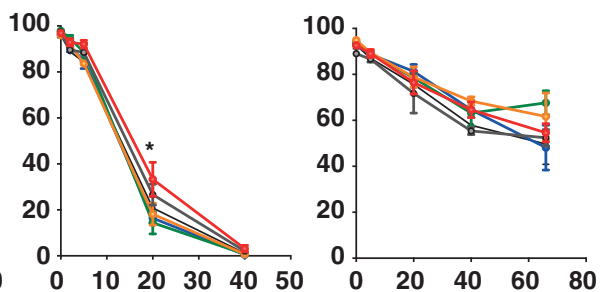

Etoposide
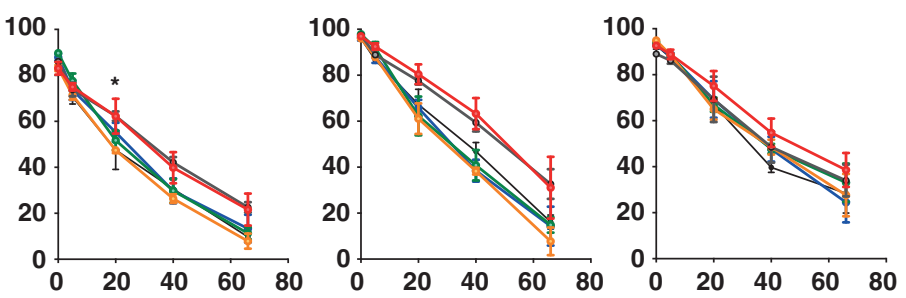

ABT-737
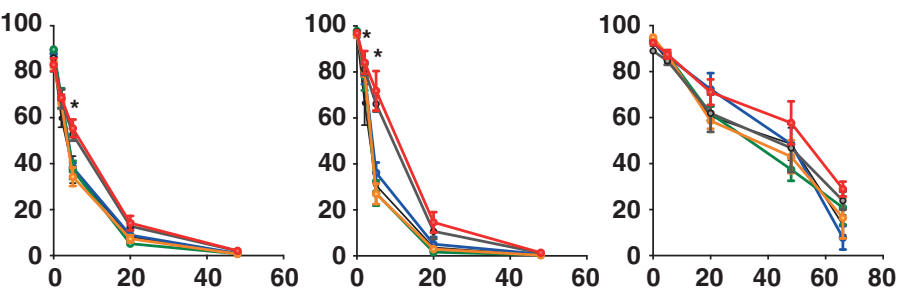

Fas ligand
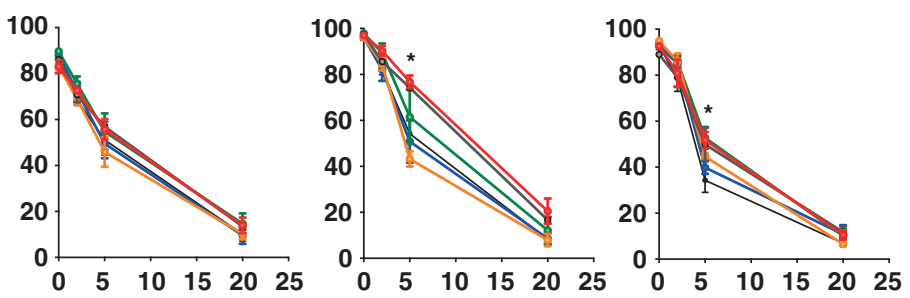

Medium
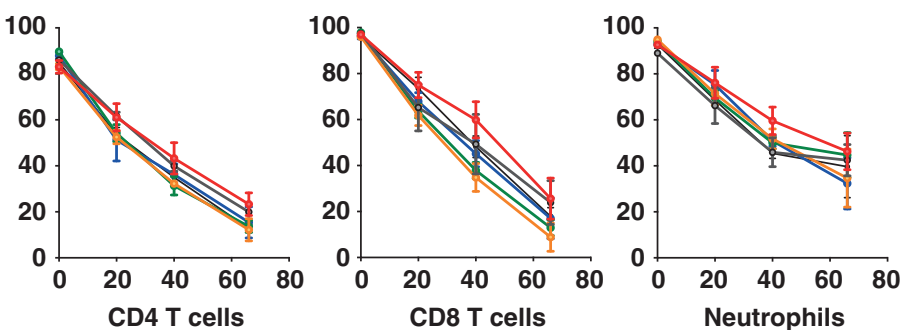

Time (h)
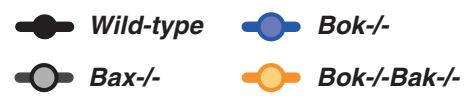

Bak-/-

Bok-/-Bax-/-

Figure 3 Sensitivity of lymphocytes from Bok ${ }^{-/-} \mathrm{Bak}^{-/-}, \mathrm{Bok}^{-/-} \mathrm{Bax}^{-/-}$and control wild-type, as well as Bok ${ }^{-/-}$, Bak ${ }^{-/-}$and Bax ${ }^{-/-}$single-knockout, mice to

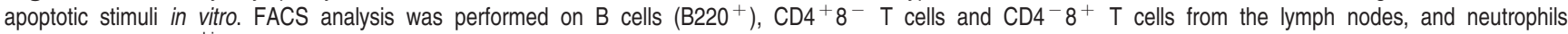
$\left(\right.$ Ter1 $\left.19^{-} \mathrm{Mac1}^{+} \mathrm{Gr1}^{\text {hi }}\right)$ were sorted from the bone marrow of 10-14-week-old mice of the indicated genotypes. These cells were then cultured in the presence of (a) dexamethasone $(1 \mu \mathrm{M})$, (b) etoposide $(1 \mu \mathrm{M})$, (c) the BH3-mimetic ABT-737 $(240 \mathrm{nM})$, which inhibits BCL-2, BCL-XL and BCL-W, ${ }^{28}(\mathbf{d})$ cross-linked FasL (100 ng/ml) ${ }^{29}$ or (e) simple medium. Cell viability was determined at the indicated times by staining with $\mathrm{PI}$ and annexin-V coupled to $\mathrm{FITC}$; annexin- $\mathrm{V}^{-} \mathrm{PI}^{-}$cells were considered alive. Data represent the mean \pm S.E.M. from 3-5 animals for each genotype. The absence of BAX alone or in combination with the absence of BOK provided a minor, but statistically significant, protection against certain apoptotic stimuli compared with wild-type cells, as indicated by * 

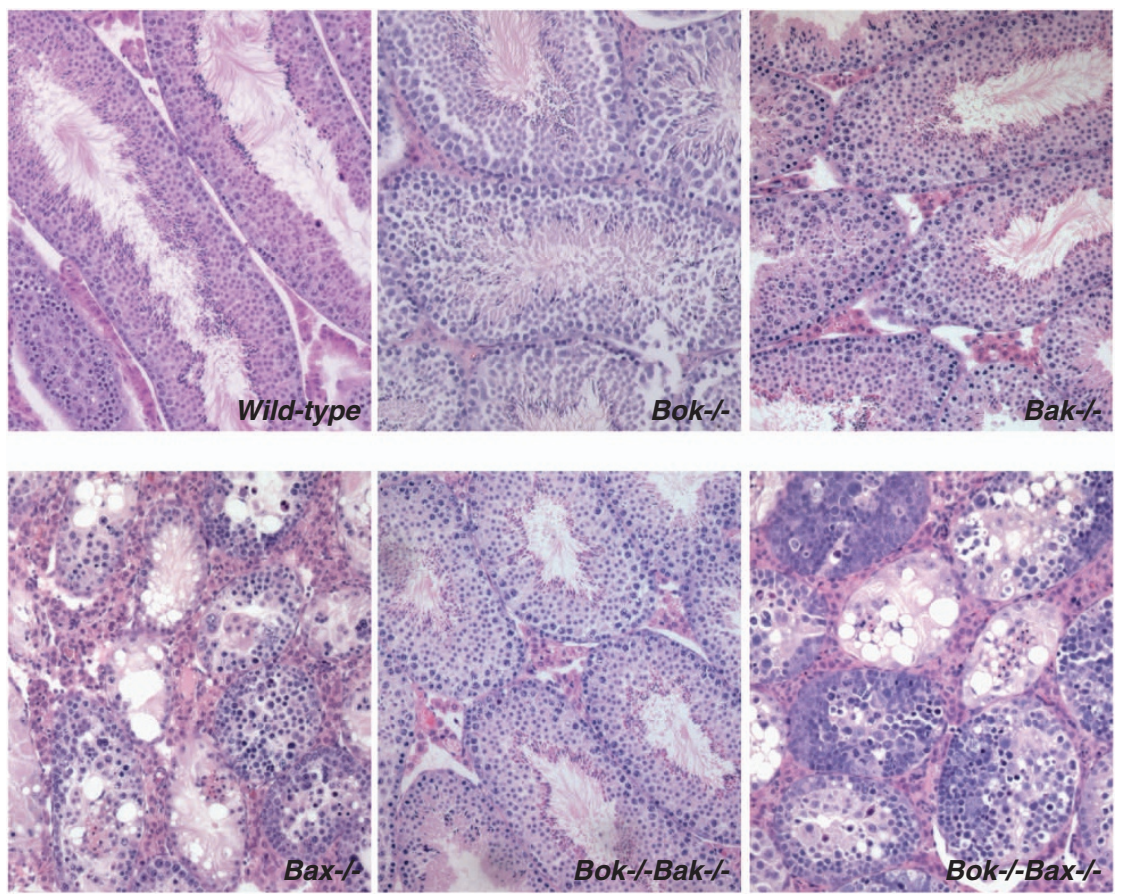

Figure 4 Histological appearance of the testes from 9-14-week-old male mice. Testes were isolated from male mice of the indicated genotypes and fixed in Bouin's solution. Microscopic analysis was performed on hematoxylin and eosin-stained sections. Testes from Bax ${ }^{-/-}$as well as Bok ${ }^{-/-}$Bax $^{-/-}$males displayed an absence of mature sperm cells. Images are shown at $\times 10$ magnification

normal in appearance (consistent with them being fertile; see above). In comparison with wild-type males, both $\mathrm{Bok}^{-/-}$ $\mathrm{Bax}^{-1-}$ and $\mathrm{Bax}^{-1-}$ males had seminiferous tubules that were smaller in diameter, lacked organization and contained no mature elongated sperm. Notably, the testes from Bok ${ }^{-1}$ ${ }^{-} \mathrm{Bax}^{-1-}$ males did not show more severe defects compared with those from $\mathrm{Bax}^{-/-}$littermates.

It has previously been reported that mice lacking BAX or BAK alone have abnormally increased numbers of undifferentiated neural progenitor cells in the subventricular neurogenic zones of the forebrain, and that this aberration is exacerbated in BAX/BAK doubly deficient mice. ${ }^{11}$ The $\mathrm{Bax}^{-1-}$ animals used in our study also displayed the aforementioned phenotype (Figure 5a), including mild hydrocephalus (Figure $5 b$ ), but, in contrast to the previous report, ${ }^{11}$ we found that the brains from $\mathrm{Bak}^{-1-}$ mice appeared similar to those from wild-type controls and displayed no evidence of abnormal neuronal cell accumulation (Figures $5 a$ and b). Although our previous study found that brains of $\mathrm{Bok}^{-/-}$mice appeared normal, ${ }^{15}$ we wanted to examine whether the combined loss of BOK and BAX, or BOK and BAK, would cause marked abnormalities that are not present in any of the single-knockout animals. However, our investigations demonstrated that loss of BOK did not further increase the neural progenitor cell accumulation (Figure $5 \mathrm{a}$ ) or extent of hydrocephalus (Figure $5 b$ ) that was elicited by the absence of BAX. Moreover, the brains from $\mathrm{Bok}^{-1-} \mathrm{Bak}^{-/-}$doubly deficient mice resembled those from wild-type and $B a k^{-/-}$controls (Figure 5).

BAX-deficient mice were previously shown to exhibit a thicker inner nuclear layer and plexiform layer in the retina compared with wild-type controls. ${ }^{16}$ Our histological analysis of retinas from $\mathrm{Bax}^{-1-}$ animals confirmed this finding (Figure 6). In contrast, the single loss of BOK or BAK alone did not have any effect on the morphology of this tissue, and even in the combined absence of both BOK and BAK, retinas remained normal in appearance (Figure 6). Finally, retinas from the $\mathrm{Bok}^{-}$ ${ }^{-} \mathrm{Bax}^{-/-}$mice were comparable to those from $\mathrm{Bax}^{-/-}$mice, with no obvious further increase in the thickness and cellularity of the various retinal layers (Figure 6).

Histological analysis of 17 additional parenchymal tissues from $\mathrm{Bok}^{-1-} \mathrm{Bak}^{-1-}$ and $\mathrm{Bok}^{-1-} \mathrm{Bax}^{-1-}$ mice revealed that they were indistinguishable from those of wild-type controls (data not shown), with the exception of the ovaries (discussed in the section below). When organs from 1-yearold $\mathrm{Bok}^{-1-} \mathrm{Bak}^{-1-}$ and $\mathrm{Bok}^{-1-} \mathrm{Bax}^{-/-}$mice were examined, we found the presence of mild leukocyte infiltrates in the kidneys, lungs and livers, but this was similarly observed in age-matched wild-type and $\mathrm{Bok}^{-/-}, \mathrm{Bax}^{-/-}$and $\mathrm{Bak}^{-/-}$ single-knockout controls (data not shown).

Collectively, these results demonstrate that BOK deficiency does not exacerbate the developmental defects caused by loss of BAX, and that combined absence of BOK and BAK does not give rise to any overt developmental abnormalities.

$\mathrm{Bok}^{-/-} \mathrm{Bax}^{-/-}$females display an increase in ovarian follicle numbers at 1 year of age. We $\mathrm{W}^{15}$ and others ${ }^{14}$ have previously shown that Bok is most highly expressed in female reproductive organs, such as the ovaries and uterus. However, in BOK-deficient females, these tissues retained normal morphology, and $\mathrm{Bok}^{-1-}$ females had normal numbers of ovarian follicles. ${ }^{15}$ We therefore explored the 

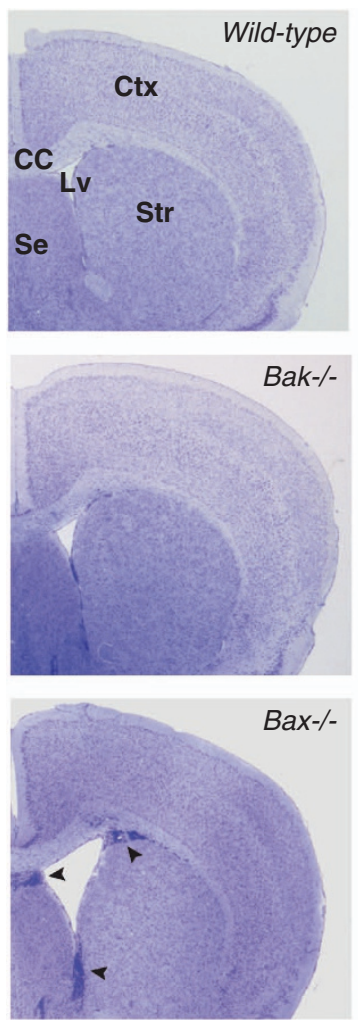
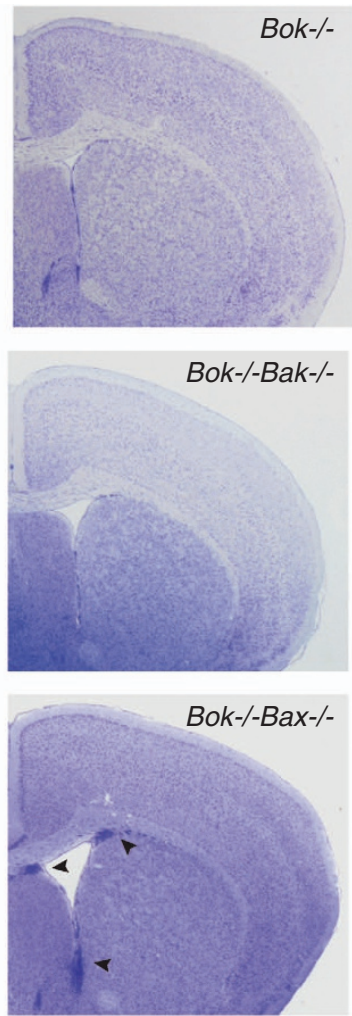

b
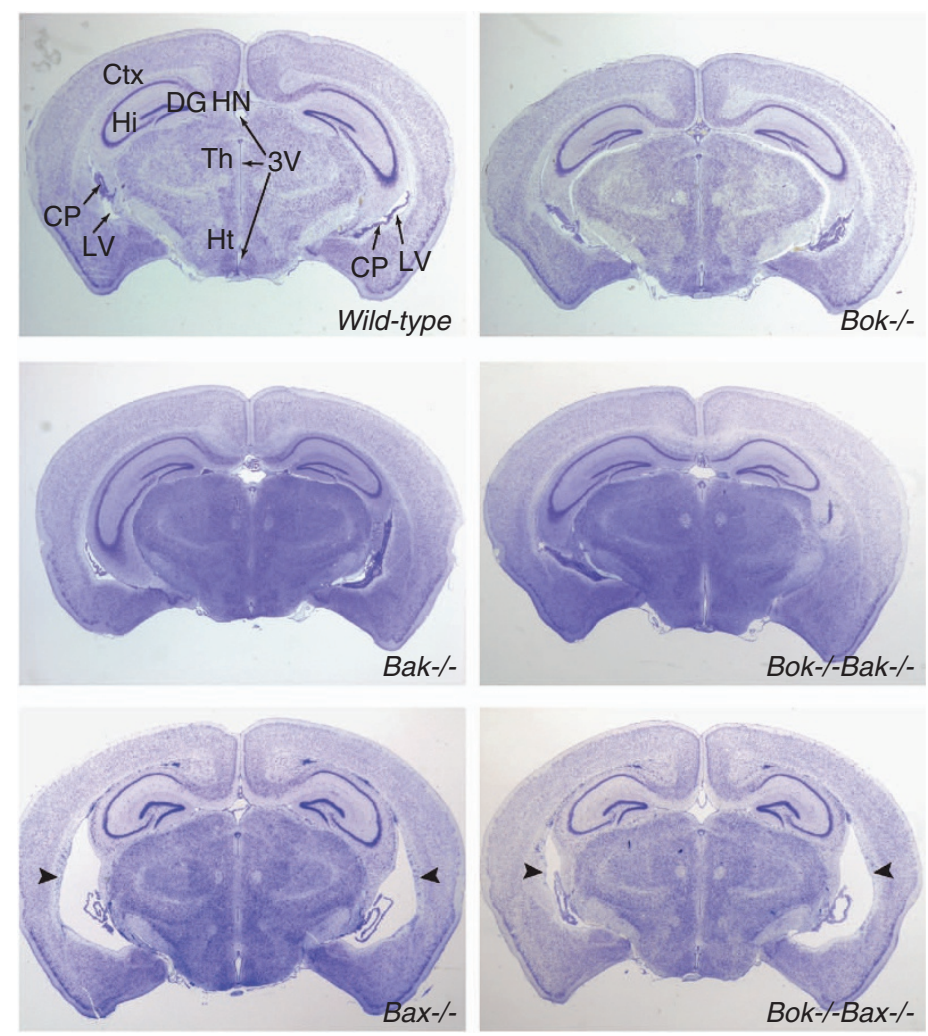

Figure 5 Histological appearance of brains from 9-14-week-old mice. Brains from young adult males of the indicated genotypes were fixed in Bouin's solution, serially sectioned and stained with cresyl violet. (a) The cerebral cortex (Ctx), corpus callosum (CC), septum (Se), striatum (Str), and lateral ventricle (LV) are labeled in the image of the wild-type animal. Black arrowheads depict the abnormal accumulation of neural progenitor cells in the forebrain subventricular neurogenic region of $B^{-1-}$ as well as $\mathrm{Bok}^{-1-} \mathrm{Bax}^{-1-}$ doubly deficient mice. (b) The third ventricle (3V), choroid plexus (CP), Ctx, dentate gyrus (DG), hippocampus (Hi), habenular nuclei (HN), hypothalamus $(\mathrm{Ht})$, LV and thalamus (Th) are labeled in the image of the wild-type animal. The absence of BAX led to an enlargement of the LVs, as observed in Bax ${ }^{-1-}$ and $\mathrm{Bok}^{-1-} \mathrm{Bax}^{-1-}$ mice, indicating mild hydrocephalus. Four animals were examined from each genotype

possibility that BOK may have overlapping functions with BAX or BAK in the female reproductive system by microscopic examination of serial sections of $\mathrm{Bok}^{-1-} \mathrm{Bak}^{-1}$ and $\mathrm{Bok}^{-1-} \mathrm{Bax}^{-1-}$ ovaries, and quantified follicle numbers at 14 weeks and 1 year of age. In young adult females (14 weeks), all single-mutant mice $\left(\mathrm{Bok}^{-/-}, \mathrm{Bak}^{-\prime}\right.$ and $\left.\mathrm{Bax}^{-1-}\right)$ and double-mutant mice $\left(\mathrm{Bok}^{-/-} \mathrm{Bak}^{-/-}\right.$ and $\mathrm{Bok}^{-1-} \mathrm{Bax}^{-1-}$ ) had normal numbers of primordial, primary and secondary follicles, but unexpectedly for yet unknown reasons, $\mathrm{Bak}^{-/-}, \mathrm{Bax}^{-/-}, \mathrm{Bok}^{-/-} \mathrm{Bak}^{-/-}$and $\mathrm{Bok}^{-1-} \mathrm{Bax}^{-1-}$ females displayed slightly lower numbers of antral follicles compared with wild-type females (Figure 7a). Aged (1-year-old) females of all genotypes exhibited a substantial depletion in follicle numbers, as expected. ${ }^{17}$ However, Bok ${ }^{-1-} \mathrm{Bax}^{-1-}$ females possessed approximately 3-5 times more primordial follicles and twice as many secondary follicles compared with wild-type and singleknockout $\left(\mathrm{Bok}^{-1-}\right.$ and $\mathrm{Bax}^{-/-}$) controls (Figure 7b). Primary and antral follicle numbers were also higher in aged $\mathrm{Bok}^{-/-} \mathrm{Bax}^{-1-}$ females compared with age-matched wildtype controls, although these latter differences were not statistically significant (Figure 7b). These findings suggest that $\mathrm{BOK}$ and $\mathrm{BAX}$ have an important overlapping role in the regulation of follicle atresia in accord with the strong Bok gene expression in the ovary. ${ }^{14,15}$

\section{Discussion}

The multi-BH domain pro-apoptotic Bcl-2 family members BAX and BAK are essential in the 'mitochondrial' apoptotic pathway. ${ }^{5,9}$ Their individual and overlapping roles in developmentally programmed and stress-induced cell death have been uncovered through the use of single- and doubleknockout mice. Although the loss of $B A X^{10}$ or $B A K^{11}$ on their own only gave rise to relatively mild phenotypic aberrations (with the exception of infertility in $\mathrm{Bax}^{-1-}$ males), the combined deficiency of both of these multi-BH domain pro-apoptotic BCL-2 family members led to profound developmental abnormalities, such as persistent interdigitating webbing in $\mathrm{Bax}^{-1-} \mathrm{Bak}^{-/-}$mice. ${ }^{11}$ Despite these defects, and the fact that BAX/BAK doubly deficient fibroblasts and lymphoid cells were markedly (in some instances almost completely) resistant to diverse apoptotic stimuli, ${ }^{11,13}$ many tissues that are widely believed to be shaped by programmed cell death during morphogenesis ${ }^{18,19}$ still appeared normal in the $\mathrm{Bax}^{-/-} \mathrm{Bak}^{-/-}$mice. ${ }^{11}$ It is therefore possible that cell 

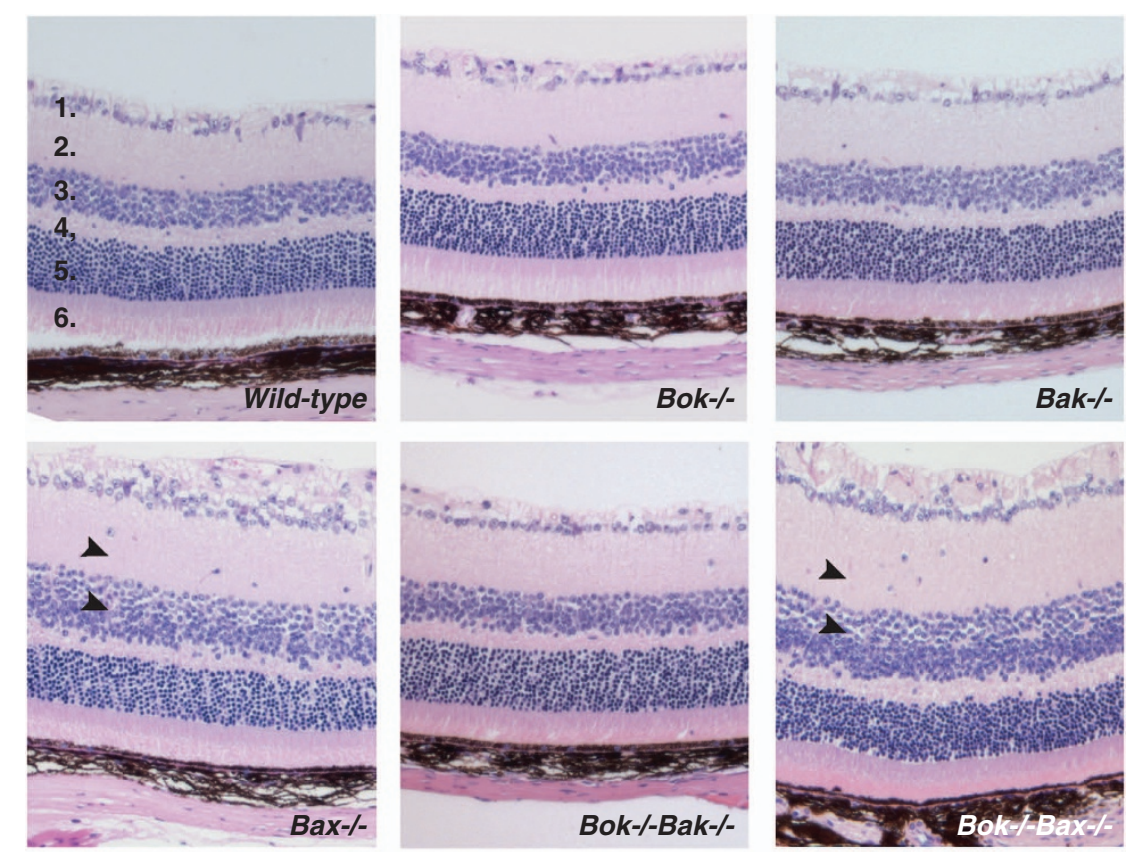

Figure 6 Histological appearance of retinas from 9-14-week-old mice. Retinas were isolated from young adult mice of the indicated genotypes and fixed in Bouin's solution. Hematoxylin and eosin-stained sections were obtained for histological analysis. Different layers of the retina are labeled: (1) ganglion cell layer, (2) inner plexiform layer, (3) inner nuclear layer, (4) outer plexiform layer, (5) outer nuclear layer and (6) outer processes of rods and cones. Black arrowheads depict layers that are thicker in $\mathrm{Bax}^{-1-}$ and $\mathrm{Bok}^{-1-} \mathrm{Bax}^{-1-}$ mice in comparison with wild-type controls. Images of the retina are shown at $\times 10$ magnification

\section{a}

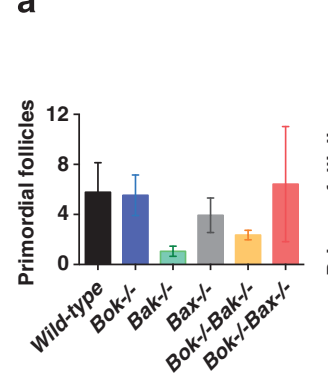

b

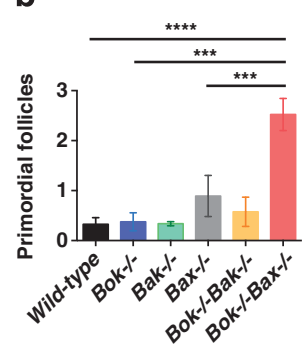

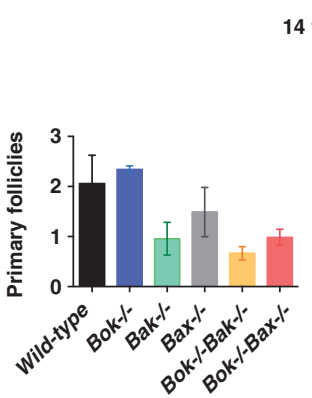

14 weeks
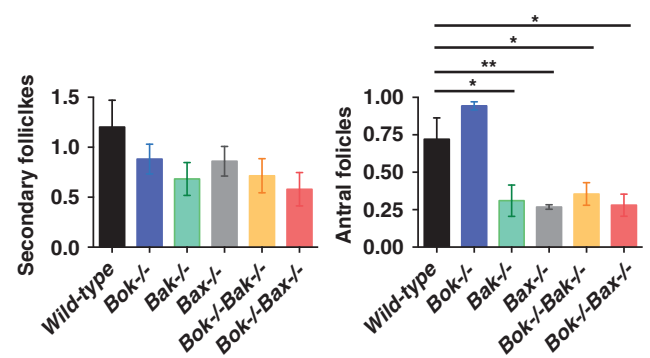

1 year
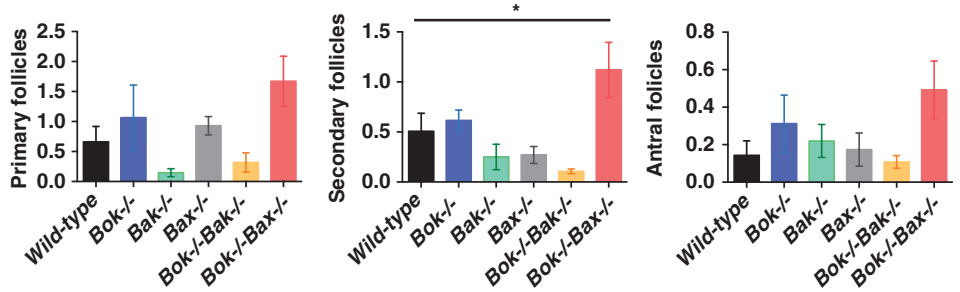

Figure 7 Ovarian follicle numbers in the ovaries are abnormally increased in aged (1-year-old) $B \mathrm{Bk}^{-/-} \mathrm{Bax}^{-/}$- females. Ovaries from (a) 9-14-week-old and (b) 1-yearold females of the indicated genotypes were serially sectioned. Follicles were counted on 5-6 evenly spaced sections, if the cross-section of a morphologically normal oocyte was contained within the section, and were classified in a consistent manner as being either in the primordial, primary, secondary or antral stage of development based on their morphology. Graphs depict the mean for each follicle type in the ovary, which are expressed as numbers $/ \mathrm{mm}^{2}$ of tissue section. ${ }^{*},{ }^{* *}$ and ${ }^{* * *}$ indicate statistically significant differences at $P<0.05,0.01$ and 0.001 , respectively. Data represent the mean $\pm S$.E.M. of follicle numbers from 3-5 females per genotype

deaths that can still occur in these $\mathrm{Bax}^{-/-} \mathrm{Bak}^{-/-}$survivors is mediated by: (1) a BAX/BAK-like process, (2) another apoptotic process (perhaps involving components of the 'death receptor' pathway) or (3) a non-apoptotic process, for example, RIPK1/3-dependent programmed necrosis (also known as necroptosis) ${ }^{20}$ or autophagic cell death. 
Because BOK has extensive amino-acid sequence similarity to BAX and BAK, it has been hypothesized to function in a BAX/BAK-like pro-apoptotic manner and may thus account for some of the cell deaths that can still occur in $\mathrm{Bax}^{-/-} \mathrm{Bak}^{-/-}$ mice. Our laboratory has previously attempted to define the role of BOK in apoptosis and animal development by characterization of $\mathrm{Bok}^{-/-}$mice, but these animals were found to be largely normal. ${ }^{15}$ To further investigate the function of BOK, and to specifically examine whether BOK may be functionally redundant with BAX or BAK, we generated $\mathrm{Bok}^{-1-} \mathrm{Bak}^{-1-}$ and $\mathrm{Bok}^{-1-} \mathrm{Bax}^{-1-}$ mice and studied them alongside wild-type as well as $\mathrm{Bok}^{-/-}, \mathrm{Bak}^{-/-}$ and $\mathrm{Bax}^{-/-}$single-knockout littermate controls at 14 weeks and 1 year of age.

In general, $\mathrm{Bok}^{-/-} \mathrm{Bak}^{-/-}$and $\mathrm{Bok}^{-/-} \mathrm{Bax}^{-/-}$mice were healthy and exhibited no obvious phenotypic abnormalities. Lymphoid organs from these animals were examined in detail by weighing, cell counting, microscopic evaluation and FACS analysis. Both the Bok ${ }^{-/-} \mathrm{Bak}^{-/-}$and Bok $\mathrm{B}^{-/-}$ $\mathrm{Bax}^{-1-}$ mice displayed normal spleen and thymus weights, and the total cellularity of all lymphoid tissues examined were also comparable to those observed in wild-type mice. In contrast to earlier reports, ${ }^{10,11}$ we failed to observe a significant increase in the spleen or thymus weights of BAX singly deficient males or females. Although we cannot conclusively explain this discrepancy in results, it may be attributed to differences in genetic background; our mice had been extensively backcrossed with C57BL/6 mice, whereas those examined earlier were on a complex mixed C57BL/ $6 \times 129$ SV background. ${ }^{10,11}$

Examination of the lymphoid tissues from young and aged $\mathrm{Bok}^{-1-} \mathrm{Bak}^{-/-}$and $\mathrm{Bok}^{-/-} \mathrm{Bax}^{-/-}$animals revealed that they were largely normal, although we observed some minor differences in particular leukocyte populations that were, however, not consistently displayed by males and females of the same genotype. For example, 1-year-old Bok ${ }^{-/-} \mathrm{Bak}^{-/-}$ and $\mathrm{Bok}^{-/-} \mathrm{Bax}^{-/-}$females showed a decrease in splenic granulocytes compared with age-matched wild-type females, but this was not observed in aged-matched $\mathrm{Bok}^{-/-} \mathrm{Bax}^{-/-}$ males. In the event that these mild alterations in leukocyte numbers are indeed a consequence of the combined loss of $B O K$ and $B A X$, or BOK and BAK, the disease-free survival of these animals up to at least 1 year demonstrates that such aberrations are insufficient to cause a major impact on the development and homeostasis of the lymphoid compartment. Because the differences observed were minor and inconsistent, we did not pursue them further.

It was therefore not surprising that lymphocytes from $\mathrm{Bok}^{-1-} \mathrm{Bak}^{-/-}$and $\mathrm{Bok}^{-/-} \mathrm{Bax}^{-/-}$mice failed to display any significant increase in resistance to diverse apoptotic stimuli compared with lymphocytes from wild-type and $\mathrm{Bok}^{-/-}, \mathrm{Bax}^{-/-}$and $\mathrm{Bak}^{-/-}$single-knockout control animals. In some cases, such as the treatment of $B$ cells with ABT-737, the absence of BAX alone was sufficient to provide a small (albeit significant) survival advantage at early time points. The additional loss of BOK on top of loss of BAX did, however, not provide greater protection than loss of BAX alone. This indicates that BOK has only a minor role, or none at all, in the apoptosis of lymphoid and myeloid cells. These results are consistent with the finding that $\mathrm{BOK}$ expression is relatively low in leukocytes, much lower, for example, compared with the female reproductive tissues. ${ }^{15,21}$

We also performed histological examinations of several non-hematopoietic organs from $\mathrm{Bok}^{-/-} \mathrm{Bax}^{-/-}$and Bok $\mathrm{Bk}^{-/-}$ $B a k^{-1-}$ mice, comparing them with wild-type as well as singleknockout controls. Consistent with previous studies, ${ }^{10,11,16}$ we found that $\mathrm{Bax}^{-/-}$animals had abnormally increased numbers of neural progenitor cells in the forebrain subventricular neurogenic zone, abnormally thick inner retinal layers (inner nuclear layer and inner plexiform layer) in the eye, as well as testicular atrophy with defective spermatogenesis in males. However, the concomitant loss of BOK together with BAX did not exacerbate or ameliorate any of these phenotypic anomalies or produce additional aberrations in other organs, with the exception of the ovaries (see below).

Previous findings demonstrated that $\mathrm{Bax}^{-/-}$females have a significant oversupply in primordial and primary follicle numbers as early as 6 weeks after birth, and this surplus was maintained even in $\mathrm{Bax}^{-/-}$females at 20-22 months of age. ${ }^{22}$ Because newborn $\mathrm{Bax}^{-/-}$females contained similar numbers of primary and primordial follicles as age-matched wild-type mice, the follicle surplus observed at later ages was attributed to decreased apoptosis of BAX-deficient oocytes and granulosa cells in these reports. To determine whether BOK may have an overlapping role with BAX or BAK in regulating folliculogenesis or atresia, we quantified follicle numbers in young ( $\sim 14$ weeks) and aged ( $\sim 1$ year) doubleand single-knockout females.

In contrast to the aforementioned study, ${ }^{22}$ we were unable to observe an abnormal increase in follicles in $\mathrm{Bax}^{-/-}$ ovaries. Likely, explanations for this discrepancy could be (subtle) differences in genetic background between the two studies (see above), and/or differences in the methods used for quantifying follicles. Notably, in earlier studies where follicle numbers had been enumerated in murine ovaries, large variations of up to 10 -fold per ovary at similar ages and/or strains were observed because of different counting methods and the use of various correction factors, ${ }^{23}$ indicating that more reliable methods need to be employed. We therefore analyzed the ovaries by first examining all the serial sections, then subsequently selecting 5-6 evenly spaced sections from each ovary for follicle quantification as previously described. ${ }^{15,24}$ Our data are presented as mean \pm S.E.M. of follicle numbers per standard area (so as not to assume that follicles are evenly distributed throughout the entire organ), rather than as an estimate of total oocyte numbers for the entire ovary. Second, earlier reports classified follicles based on their health status (healthy/atretic) and only quantified healthy, non-atretic follicles. ${ }^{22}$ However, as the morphology of an atretic follicle is yet to be accurately established, we decided to instead reliably group follicles into four classes - primordial, primary, secondary and antral depending on their morphology, and counted those follicles that contained a cross-section of the oocyte.

We found that aged (1-year-old) Bok ${ }^{-/-} \mathrm{Bax}^{-/-}$females, but not $\mathrm{Bax}^{-1-}$ single-mutant females, possessed a surplus of follicles at all developmental stages compared with agedmatched wild-type controls. Because this surplus of follicles was not observed at 14 weeks, it appears unlikely that $B o k^{-1}$

$\mathrm{Bax}^{-1-}$ females were endowed with more primordial 
follicles at birth. Thus, these observations indicate that BOK and $\mathrm{BAX}$ may function together to regulate follicle atresia. A reduction in the demise of developing ovarian follicles may result in the accumulation of hormonally active follicles. This in turn can likely suppress the activation of primordial follicles such that in the absence of both BOK and BAX, fewer primordial follicles are activated and can thus persist for longer periods.

As BOK is highly expressed in reproductive organs and granulosa cells, ${ }^{14,15}$ it is not surprising that BOK may only exert its function in limited cell types and/or under particular stress conditions. The processes and genes that regulate oocyte survival or elimination are complex and have not been fully elucidated to date, but it is clear that the BCL-2 family has a central role. ${ }^{25}$ Although $\mathrm{BOK}$ is strongly expressed in the oocytes of fetal human ovaries and in oocytes within primordial and growing follicles in adults, its function remains unknown. ${ }^{26}$ However, there is increasing evidence that several cell death regulators are required to act collectively and/or in sequence to control follicle apoptosis. For instance, loss of PUMA conferred some protection $(\sim 15 \%)$ to primordial follicles against $\gamma$-irradiation, whereas loss of NOXA had no significant impact; but the combined absence of both PUMA and NOXA provided substantial protection (up to $95 \%){ }^{24}$ Hence, the loss of certain genes may have profound consequences on oocytes, whereas others may exert only relatively mild effects. The findings from our studies demonstrate that the combined loss of BOK and BAX has a greater influence on follicle numbers than the single loss of either pro-apoptotic protein alone. This provides the first in vivo evidence that BOK may exert an overlapping pro-apoptotic function with BAX in the context of follicle atresia.

In conclusion, we have examined $\mathrm{Bok}^{-1-} \mathrm{Bak}^{-1-}$ and $\mathrm{Bok}^{-/-} \mathrm{Bax}^{-/-}$double-knockout animals and demonstrated that apart from the defects caused by the single loss of BAX or BAK alone, the combined absence of BOK with BAX, or BOK with BAK, did not result in additional phenotypic anomalies in most tissues examined (apart from the ovaries). This may indicate that BOK does not have a crucial pro-apoptotic function overlapping with BAX or BAK in these normally developed organs. Given that BAX and BAK are key factors in apoptosis that regulate and shape the hematopoietic system and several epithelial and neuronal tissues, it may come across as a surprise that BOK, a close relative, does not carry out similar roles. However, we cannot eliminate the possibility that certain developmentally programmed cell deaths can still be carried out efficiently when one of BOK, BAX or BAK remains present. To test this hypothesis, it will be imperative to generate $\mathrm{Bok}^{-/-} \mathrm{Bax}^{-/-} \mathrm{Bak}^{-/-}$triple-knockout mice. Alternatively, it is possible that the developmental cell deaths that shape the tissues in $\mathrm{Bax}^{-/-} \mathrm{Bak}^{-/-}$mice are mediated by 'BCL-2-regulated' independent mechanisms, perhaps involving the 'death receptor' apoptotic pathway. Necroptosis and/or autophagy may also contribute to morphogenesis and the maintenance of organ homeostasis. It will be exciting to examine the contribution, if any, of such processes by generating complex compound knockout mice that lack BAX/BAK (and possibly also BOK) plus critical regulators of these processes (e.g., RIPK3 for necroptosis).
Materials and Methods

Mice. The $B o k^{-/-}{ }^{15} \mathrm{Bak}^{-/-11}$ and $\mathrm{Bax}^{-/-10}$ mice have all been previously described. Bok ${ }^{-1-}$ mice were generated on a C57BL/6 background using C57BL/6-derived ES cells. Mice deficient for BAX or BAK had originally been generated on a mixed C57BL/6 $\times 129 S V$ background, using 129SV-derived ES cells, but were subsequently backcrossed with C57BL/6 mice for more than 12 generations. To produce $\mathrm{Bok}^{-1-} \mathrm{Bax}^{-1-}$ animals, $\mathrm{Bok}^{-1-}$ mice were bred with $\mathrm{Bax}^{+/-}$mice to produce $\mathrm{Bok}^{+/-} \mathrm{Bax}^{+/-}$offspring. Animals of this genotype were crossed to $\mathrm{Bok}^{-1-}$ mice to obtain $\mathrm{Bok}^{-1-} \mathrm{Bax}^{+/-}$mice, which were then intercrossed to produce $\mathrm{Bok}^{-1-} \mathrm{Bax}^{-1-}$ animals. This strategy was similarly employed to produce $\mathrm{Bok}^{-1-} \mathrm{Bak}^{-1-}$ mice. All experiments with mice were performed with the approval of the Walter and Eliza Hall Institute Animal Ethics Committee and according to the Australian code of practice for the care and use of animals for scientific purposes.

PCR. Tail tips from 3-4-week-old mice were taken and digested with $200 \mu \mathrm{l}$ of DirectPCR Lysis Reagent (tail) containing $0.4 \mathrm{mg} / \mathrm{ml}$ Proteinase K (Sigma-Aldrich St. Louis, MO, USA) overnight at $55^{\circ} \mathrm{C}$ with agitation. Lysates were then heat inactivated for $45 \mathrm{~min}$ at $85^{\circ} \mathrm{C}$, and subsequently used for PCR reactions. Mice deficient for the Bok gene were identified by genotyping as previously described. ${ }^{15}$ Presence or absence of the Bak gene was determined using a three-primer PCR reaction with a common primer ( $5^{\prime}$-GAGCCATGAAGATGTTTAGC- $\left.3^{\prime}\right)$, and two reverse primers (5'-GCCCGGTTCTTTTTGTCAAGACCGA-3' and $5^{\prime}$-CCAACCAATCCTTTGTAATG- $3^{\prime}$ ). The wild-type and deleted Bak alleles produced band sizes of 580 and $1000 \mathrm{bp}$, respectively, when resolved on $2 \%$ agarose gel. PCR primers for analysis of the Bax locus utilized a common primer ( $5^{\prime}$ GTTGACCAGAGTGGCGTAGG-3') in combination with two reverse primers $\left(5^{\prime}\right.$ AGCTGATCAGAACCATCATG- $3^{\prime}$ and $5^{\prime}$ - CCGCTTCCATTGCTCAGCGG- $3^{\prime}$ ) to generate products of 304 and $507 \mathrm{bp}$, corresponding to the wild-type and knockout allele, respectively (Supplementary Figure 1).

Histology. Mouse organs were fixed in either $10 \%$ buffered formalin or Bouin's solution and subsequently embedded in paraffin. Slides were prepared and stained with haematoxylin and eosin. Whole brains were collected into Bouin's fixative, embedded in paraffin and serial sections prepared for staining with cresyl violet dye. Histological examination of the organs and brains were performed with a compound microscope and dissection microscope (both from Zeiss, Oberkochen, Germany), and photographed with a digital camera (AxioCam HRc Zeiss). Whole ovaries were harvested into Bouin's solution and serially sectioned. Follicles were classified into various developmental stages, and those containing a cross-section of the oocyte were counted on 5-6 evenly spaced sections across each ovary, as described. ${ }^{15,24}$ Follicle numbers are presented as the mean \pm S.E.M. $/ \mathrm{mm}^{2}$

Hematopoietic analysis, immunofluorescence staining and flow-cytometric analysis. Peripheral blood was collected by cardiac puncture after euthanasia, and hematological analysis was performed using the ADVIA automated hematology system (Bayer, Tarrytown, NY, USA). Single-cell suspensions were prepared from the thymus, spleen, lymph nodes and bone marrow (two tibias and two femurs), and viable cell numbers were enumerated with the automated CASY counter (Basel, Switzerland). The cell subset composition of these lymphoid organs was determined by staining with fluorochrome (red phycoerythrin (R-PE), allophycocyanin (APC) or fluorescein isothiocyanate (FITC))-conjugated monoclonal antibodies specific to cell lineage markers (see above) and FACS analysis. Antibodies used for immunofluorescence staining and FACS analysis or cell sorting included anti-CD4 (YTA321 or H129), anti-CD8 (YTS169), anti-B220 (RA3-6B2), anti-lgM (5.1), anti-IgD (1126C), anti-cKit (ACK-4), anti-Mac-1 (MI/70), anti-Gr-1 (RB6-8C5) and anti-Ter119, conjugated to FITC (Caltag, Buckingham, UK), R-PE or APC (both from Prozyme, Hayward, CA, USA). FACS analysis of hematopoietic tissues (spleen, bone marrow, thymus and lymph nodes) was carried out on an LSR1 (Becton Dickinson, Franklin Lakes, NJ, USA) machine, and cell sorting was performed using a MoFlo (Cytomation, Boulder, CO, USA) high-speed cell sorter as described. ${ }^{27}$

Cell culture and cell survival assays. Lymphoid and myeloid cell subsets were isolated by FACS sorting based on their surface-marker expression profiles as described above. Immature $\mathrm{CD} 4^{+} \mathrm{CD}^{+}$(double-positive) thymocytes were sorted from the thymus, mature $\mathrm{CD} 4^{+} \mathrm{CD}^{-}$and $\mathrm{CD} 4^{-} \mathrm{CD} 8^{+} \mathrm{T}$ cells, mature $\mathrm{B}_{2} 2 \mathrm{O}^{+} \mathrm{B}$ cells were sorted from the lymph nodes, and $\mathrm{Gr}-1^{+} \mathrm{Mac}-1^{+}$ 
granulocytes were sorted from the bone marrow. All cells were cultured at $37^{\circ} \mathrm{C}$ in a humidified $10 \% \mathrm{CO}_{2}$ incubator in high-glucose Dulbecco's Modified Eagle's medium supplemented with $10 \%$ heat-inactivated fetal calf serum (JRH Biosciences, Lenexa, KS, USA), $50 \mu \mathrm{M}$ 2-mercaptoethanol and $100 \mu \mathrm{M}$ asparagine. Sorted cells were cultured in 96-well flat bottom plates at a density of $3-5 \times 10^{5}$ cells $/ \mathrm{ml}$. Apoptotic stimuli applied included dexamethasone $(1 \mu \mathrm{M})$, etoposide $(1 \mu \mathrm{M})$, ABT-737 $(240 \mathrm{nM})$ or FLAG-tagged FasL (100 ng/ml; Enzo Life Sciences, Farmingdale, NY, USA) cross-linked with anti-Flag M2 antibody ( $2 \mu \mathrm{g} /$ $\mathrm{ml}$; Sigma, St Louis, MO, USA). Death by cytokine deprivation was mimicked by plating cells in simple culture medium without the addition of cytokines. To examine cell survival, cells were stained with $5 \mu \mathrm{g} / \mathrm{ml}$ of propidium iodide (PI) plus FITC-conjugated annexin-V and analyzed by flow cytometry on an LSR1 (Becton Dickinson) machine at various time intervals. Viable cells were defined as those that were not stained by either PI or FITC-annexin-V $\left(\mathrm{FITC}^{-} \mathrm{PI}^{-}\right)$.

Statistical analysis. All statistical analyses were performed using the oneway ANOVA, and $P$-values $<0.05$ were considered significant. The frequencies of genotypes obtained were compared with the expected Mendelian frequency using Pearson's $\chi^{2}$-test and Fisher's exact test on the Stata/IC 10.0 software (StataCorp LP; Lakeway Drive, TX, USA).

\section{Conflict of Interest}

The authors declare no conflict of interest.

Acknowledgements. We thank Drs. JM Adams, S Cory, LA O'Reilly, D Gray, $M$ Herold and G Kelly for their advice and providing mice and reagents; G Siciliano, S Allan and J Coughlin for animal care; J Corbin for automated blood analysis; B Helbert and C Young for genotyping; E Tsui for histological preparations; and Dr. F Battye and his team for cell sorting. This work was supported by grants and fellowships from the Leukemia Research Foundation (to FK), the National Health and Medical Research Council (Program Grant no. 461221 and 1016701; NHMRC Australia Fellowship and NHMRC Research Fellowships 1020363 to AS, 1042629 to PB and 575512 to AKV), two Specialised Centre of Research Grants for the Leukaemia and Lymphoma Society of America (LLS 7001-13 and 7417-07), the Swiss National Science Foundation (to TK, PP0033_119203) and operational infrastructure grants through the Australian Government (IRISS) and the Victorian State Government (OIS).

1. Strasser A, Cory S, Adams JM. Deciphering the rules of programmed cell death to improve therapy of cancer and other diseases. EMBO J 2011; 30: 3667-3683.

2. Hotchkiss RS, Strasser A, McDunn JE, Swanson PE. Cell death. N Eng J Med 2009; 361: $1570-1583$

3. Strasser A, Harris AW, Huang DCS, Krammer PH, Cory S. Bcl-2 and Fas/APO-1 regulate distinct pathways to lymphocyte apoptosis. EMBO J 1995; 14: 6136-6147.

4. Strasser A, Jost PJ, Nagata S. The many roles of FAS receptor signaling in the immune system. Immunity 2009; 30: 180-192.

5. Youle RJ, Strasser A. The BCL-2 protein family: opposing activities that mediate cell death. Nat Rev Mol Cell Biol 2008; 9: 47-59.

6. Puthalakath $\mathrm{H}$, Strasser $\mathrm{A}$. Keeping killers on a tight leash: transcriptional and posttranslational control of the pro-apoptotic activity of BH3-only proteins. Cell Death Differ 2002; 9: 505-512.

7. Merino D, Giam M, Hughes PD, Siggs OM, Heger K, O'Reilly LA et al. The role of BH3-only protein Bim extends beyond inhibiting Bcl-2-like prosurvival proteins. J Cell Biol 2009; 186: 355-362.

8. Llambi F, Moldoveanu T, Tait SW, Bouchier-Hayes L, Temirov J, McCormick LL et al. A Unified Model of Mammalian BCL-2 Protein Family Interactions at the Mitochondria. Mol Cell 2011; 44: 517-531.
9. Chipuk JE, Green DR. How do BCL-2 proteins induce mitochondrial outer membrane permeabilization? Trends Cell Biol 2008; 18: 157-164.

10. Knudson CM, Tung KSK, Tourtellotte WG, Brown GAJ, Korsmeyer SJ. Bax-deficient mice with lymphoid hyperplasia and male germ cell death. Science 1995; 270: 96-99.

11. Lindsten T, Ross AJ, King A, Zong W, Rathmell JC, Shiels HA et al. The combined functions of proapoptotic Bcl-2 family members Bak and Bax are essential for normal development of multiple tissues. Mol Cell 2000; 6: 1389-1399.

12. Mason KD, Lin A, Robb L, Josefsson EC, Henley KJ, Gray DH et al. Proapoptotic Bak and Bax guard against fatal systemic and organ-specific autoimmune disease. Proc Natl Acad Sci USA 2013; 110: 2599-2604.

13. Rathmell JC, Lindsten T, Zong W-X, Cinalli RM, Thompson CB. Deficiency in Bak and Bax perturbs thymic selection and lymphoid homeostasis. Nat Immunol 2002; 3: 932-939.

14. Hsu SY, Kaipia A, McGee E, Lomeli M, Hsueh AJW. Bok is a pro-apoptotic Bcl-2 protein with restricted expression in reproductive tissues and heterodimerizes with selective anti-apoptotic Bcl-2 family members. Proc Natl Acad Sci USA 1997; 94: $12401-12406$.

15. Ke F, Voss A, Kerr JB, O'Reilly LA, Tai L, Echeverry N et al. BCL-2 family member BOK is widely expressed but its loss has only minimal impact in mice. Cell Death Differ 2012; 19: 915-925.

16. Pequignot MO, Provost AC, Salle S, Taupin P, Sainton KM, Marchant $D$ et al. Major role of $\mathrm{BAX}$ in apoptosis during retinal development and in establishment of a functional postnatal retina. Dev Dyn 2003; 228: 231-238.

17. Gosden RG, Laing SC, Felicio LS, Nelson JF, Finch CE. Imminent oocyte exhaustion and reduced follicular recruitment mark the transition to acyclicity in aging $\mathrm{C} 57 \mathrm{BL} / 6 \mathrm{~J}$ mice. Biol Reprod 1983; 28: 255-260.

18. Vaux DL, Korsmeyer SJ. Cell death in development. Cell 1999; 96: 245-254.

19. Lockshin RA, Zakeri Z. Programmed cell death and apoptosis: origins of the theory. Nat Rev Mol Cell Biol 2001; 2: 545-550.

20. Vanlangenakker N, Vanden Berghe T, Vandenabeele P. Many stimuli pull the necrotic trigger, an overview. Cell Death Differ 2012; 19: 75-86.

21. Echeverry N, Bachmann D, Ke F, Strasser A, Simon HU, Kaufmann T. Intracellular localization of the BCL-2 family member BOK and functional implications. Cell Death Differ 2013; 20: 785-799.

22. Perez Gl, Robles R, Knudson CM, Flaws JA, Korsmeyer SJ, Tilly JL. Prolongation of ovarian lifespan into advanced chronological age by Bax-deficiency. Nat Genet 1999; 21: 200-203.

23. Myers M, Britt KL, Wreford NG, Ebling FJ, Kerr JB. Methods for quantifying follicular numbers within the mouse ovary. Reproduction 2004; 127: 569-580.

24. Kerr JB, Hutt KJ, Michalak EM, Cook M, Vandenberg CJ, Liew SH et al. DNA damageinduced primordial follicle oocyte apoptosis and loss of fertility require TAp63-mediated induction of Puma and Noxa. Mol Cell 2012; 48: 343-352.

25. Boumela I, Assou S, Aouacheria A, Haouzi D, Dechaud H, De Vos J et al. Involvement of $\mathrm{BCL} 2$ family members in the regulation of human oocyte and early embryo survival and death: gene expression and beyond. Reproduction 2011; 141: 549-561.

26. Jaaskelainen M, Nieminen A, Pokkyla RM, Kauppinen M, Liakka A, Heikinheimo M et al. Regulation of cell death in human fetal and adult ovaries-role of Bok and $\mathrm{Bcl}-\mathrm{X}(\mathrm{L})$. Mol Cell Endocrinol 2010; 330: 17-24.

27. Strasser A, Harris AW, Cory S. Bcl-2 transgene inhibits T cell death and perturbs thymic self-censorship. Cell 1991; 67: 889-899.

28. Oltersdorf T, Elmore SW, Shoemaker AR, Armstrong RC, Augeri DJ, Belli BA et al. An inhibitor of Bcl-2 family proteins induces regression of solid tumours. Nature 2005; 435 : 677-681.

29. O'Reilly LA, Tai L, Lee L, Kruse EA, Grabow S, Fairlie WD et al. Membrane-bound Fas ligand only is essential for Fas-induced apoptosis. Nature 2009; 461: 659-663.

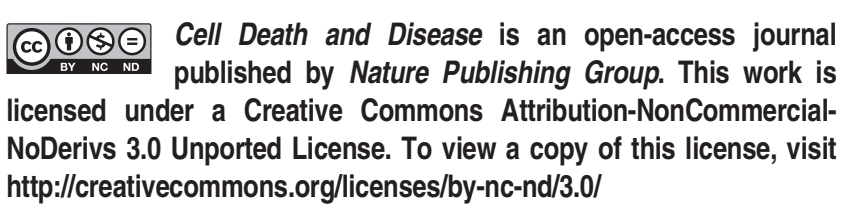

cc) (i) $\Theta$ Cell Death and Disease is an open-access journal licensed under a Creative Commons Attribution-NonCommercialNoDerivs 3.0 Unported License. To view a copy of this license, visit http://creativecommons.org/licenses/by-nc-nd/3.0/ 